\title{
Possible impact and adaptation to climate change in livestock production in Southern Africa
}

\author{
Never Assan \\ Zimbabwe Open University, Faculty of Science and Technology, Department of Agriculture Management, \\ Bulawayo Region, Box 3550, Bulawayo, Zimbabwe.
}

\begin{abstract}
Southern Africa is one of the most vulnerable regions to climate variability and change because of multiple existing climatic stresses and low adaptive capacity. It is now indisputable that climate change will have a grave effect on livestock production in Southern Africa, coming as an additional factor affecting livestock production that is already highly dynamic and facing a host of challenges. Climatic change is threatening the sustainability of livestock production systems by reinforcing existing stressors such as heat stress, droughts, and flooding events which have lead to reductions in livestock productivity. This review attempt to explore the likely impacts of climate change on livestock production systems, and discuss influence of climate change on water and feeds, livestock genetics and breeding, and animal health. The expected responses to climate induced environmental stressors on livestock production are also highlighted. This is on the understanding that the impact of climate change on livestock production through natural disasters and environmental challenges are likely to affect Southern Africa indiscriminately. Livestock production systems need to adjust through adoption of possible strategies to reduce vulnerability to climate change which affects livestock production in various direct and indirect ways. In order to be able to adequately address livestock production challenges in the context of climate, there is need for Southern African to carry out thorough climatic vulnerability and adaptation assessments, before responses are suggested. Lack of comprehensive training of experts in carrying out vulnerability and adaptation assessments on livestock production, which is crucial in order to develop climate change adaptation measures on livestock production has been a major concern. The vulnerability to climate change impact is a function of several biophysical and socioeconomic factors which need to be taken into account.
\end{abstract}

Keywords: Adaptation, Climate Change, Impact, Livestock Production, Southern Africa

\section{Introduction}

Climate change is defined as the significant variation of the mean state of climate relevant variables such as temperature, precipitation and wind in a certain period of time, commonly over 30 years (IPCC 2007). Current evidence point to the fact that climate change is a major concern that will define livestock production systems and livestock productivity in Southern Africa and world over ( [1]Miraglia et al., 2009; [2]Van den Bossche and Coetzer, 2008; [3]Forman et al., 2008; [4]Black et al., 2008; [5]Pinto et al., 2008). In different parts of southern Africa (e.g., Angola, Namibia, Mozambique, Malawi, Zambia), a significant increase in heavy rainfall events has also been observed ([6]Usman and Reason, 2004), including evidence for changes in seasonality and weather extremes ([7[Tadross et al., 2005a; [8]New et al., 2006). In the future, the frequency of extremely dry winters and springs in southern Africa is likely to increase alongside the frequency of extremely wet summers which will impact on livestock production. Livestock production systems will be influenced by climate change in many ways which include the changes in the primary productivity of forage and rangelands and the direct effects of weather and extreme events on animal health, growth and reproduction ([9]Smit et al 1996). The climate impacts anticipated for Southern Africa are similar to those being experienced around the world: general warming (day and night temperatures all year round); changes in rainfall timing and quantities; changes in seasons (longer summers); increased climate variability (e.g. floods, droughts and heat waves); higher sea-levels; and increasing frequency and intensity of extreme weather events [10](IPPC, 2007). This is on the background that the effects of climate change on crops are well known, much less is known about the effects of climate change on livestock. Unfortunately, livestock production assumes an overriding emphasis as one of the core sectors to solve the current food challenges and bringing future food sustainability in Southern Africa. The Intergovernmental Panel on Climate Change [10](IPCC, 2007) is now overwhelmingly convinced that climate change is real, that it will become worse, and that the poorest regions and small scale famers will be the worst affected. On the other hand, it is believed that livestock production will be one of the most susceptible sector to climate change due to changes in hydrological cycle, temperature balance and rainfall patterns which have a negative effect on livestock productivity ([11]Mwiturubani, 2010). The direct effects of air temperature, humidity and wind speed capable of influencing growth rate, milk production, wool production and reproduction have been reported by [12]Houghton, (2001) and [13]Rust and Rust (2013). The quantity and 
quality of livestock feed stuffs such as pasture and forage can be indirectly affected by climate change [14](McCarthy et al., 2001) significantly influencing farmers` livestock selection choices. Also, the severity and distribution of livestock diseases and parasites is conditioned by climate change [15](Seo and Mendelsohn, 2008; [16]Thornton and Herrero, 2008). The challenges of climate change will call for a balanced type of animal which can produce in stressful environment as a result the utilization of adaptive livestock genotypes which may sustain production in this regard. Climate change taking the centre stage the merit of indigenous livestock apart from their ability to adapt to stressful environment are a valuable asset to the smallholder farmers as they provide their basic needs. The economic impact of climate change/variability may be broadly captured as a combination of direct impact, indirect impacts and reduction in future livestock activities.

\section{Impact Of Climate Change On Feed Resources}

Climate change will have far-reaching consequences for livestock production, mainly arising from its impact on grassland and rangeland productivity. In Southern Africa, climate change has already begun impacting on ecosystems, mostly to their detriment. Changes in a variety of ecosystems are already being detected, particularly in southern African ecosystems, at a faster rate than anticipated. Predicted effects of climate change are a threat to many plant species and even some ecosystems, as identified by both the Millennium Ecosystem Assessment[17](MEA, 2005). The effects of climate change such as warmer temperatures and rainfall patterns produce a greater impact of rangeland biodiversity which influence livestock production. Its indisputable that grass, legumes and shrub composition in rangeland constitute the important determinant of livestock productivity. However, the climatic change induced interactions of humidity, temperatures and rainfall are likely to influence the distribution of these on rangelands. Moreover, rising temperatures facilitate the spread of "invasive alien species" (like weeds) which themselves are a significant threat to ecosystems and agriculture, and less palatable to support livestock production. The rainfall regimes will determine the existence of certain grass, legume and shrubs species, which in turn will translate into livestock feed resources availability. Climate change related factors which have negatively impacted on livestock feed resources include decline in rainfall amounts and intensity, reduced length of rain season and increasing warm and occasionally very hot conditions which has directly affected livestock performance. As a result livestock production systems which are heavily dependent on the environment there is need to adapt to higher ambient temperatures and lower nutritional value of feed resources which has influenced level of production. In Zimbabwe, for example, there are more cooler and hotter days, and the length and severity of the drier periods is increasing [18](FAO, 2004). However, indigenous livestock species over the decades have managed to survive, reproduce and produce in already stressed agro-ecological environmental conditions, characterised with low levels of nutrition and inadequate resource feed resources. [16]Thornton and Herrero (2008) explores the indirect effect of climate change on feed resources, citing its significant impact on livestock productivity. Suggest that one of the most evident and important effects of climate change on livestock production is mediated through changes in feed resources which will affect the carrying capacity of rangelands, the buffering ability of ecosystems and their sustainability. Climate change impact will be greatest felt in grazing systems, especially in the arid and semi arid tropics, where livestock production systems have a tendency of accelerating ecological destruction through climatic variability. This scenario will not augur well for sustainable future livestock productivity in the context of climate change. Overgrazing has been a result of high stocking rates in areas where feed and water is scarce. Climate change has caused a marked seasonality in feed quantity and quality on rangelands in Southern Africa, which have been worsened by the frequent dry spells in some part of the region. Lack of high quality feed throughout the year on rangeland has been cited as the major constraint in livestock production especially in smallholder farming sectors. Due to climatic induced factors the vegetation dynamics has changed affecting the grazing capacity. Temperature increases and rainfall decreases due to climatic variability has affected the grasses and legumes species on rangelands promoting especially unpalatable species reducing livestock productivity. Introduction of adaptable grasses and legumes species must exhibit good response to both biotic and abiotic constraints for survival. Rangelands are complex plant ecosystems, hence the future impacts of climate change on the quantity and quality of nutrition for grazing livestock will be difficult to predict. Introduction of adapted pasture species will mitigate the effects of climate change. These should have wide spread adaptation to environmental stresses, ease of management and acceptability by livestock farmers. The optimal growth for different grasses and legumes species will change in the context of climate change, species which will alter their competition dynamics and diversity of mixed species definitely will change. Such changes could have enormous consequences on livestock production system which is mainly dependent on these rangelands through the numbers of animals that are kept, livestock productivity itself and potential loss of animals during the dry spells. There is need to continue to evaluate forage legumes for the effects of anti-nutritional factors to improve their use in livestock production in the context of climate change. Opportunities for improving the nutrition of livestock do exist, for instance, multipurpose legume trees adapted to local environment can provide high-quality feed and improve soil fertility [19](Lenné and Thomas 2006). 
Particular attention should be given to identification and use of native pasture plants and forage shrubs for use in degraded environments as a result of climatic variability. Matching feed resources to livestock requirement in adverse condition will be a grave task. Research institutions should start producing forage varieties that are well adapted to stressful environmental conditions. The efforts of new approaches such as marker assisted selection on forages could be exploited to produce grasses and legumes varieties which can sustainably support livestock production in the predicted uncertainties of climatic variability. Forage varieties with multiple attributes to overcome a range of biotic and abiotic constraints induced by climate change are needed. Promoting adapted pasture species will play a major role in reducing vulnerability of feed resources to climate change. This improves preparedness for harsh climate induced conditions on livestock production itself and thus substantially raising survival rates and livestock performance due to availability of feed resources.

\section{Impact Of Climate Change On Water Resources}

Climate change will have far-reaching consequences for livestock production, mainly arising from its impact on rainfall patterns which later determines the quantity and quality of grassland and rangeland productivity. Water resources in particular comprise one sector that is highly dependent on and influenced by climate change [20](ISS, 2010). Some countries in Southern Africa are already experiencing considerable water stress as a result of insufficient and unreliable rainfall that changes rainfall patterns or causes flooding. The [10]IPCC (2007) is confident that the overall net impact of climate change on water resources and freshwater ecosystems will be negative due to diminished quantity and quality of available water. In Southern Africa, climate change has already begun impacting on ecosystems, mostly to their detriment. Predicted effects of climate change are a threat to many water plant species and even some ecosystems, as identified by both the Millennium Ecosystem Assessment [17](MEA, 2005). The availability of water resources is strongly related to the amount and timing of runoff and rainfall. Droughts are likely to become more widespread, while increases in heavy rainfall events would produce more flooding [21](Easterling et al., 2007; [22]Kundzewicz et al., 2007). Water quality is important for livestock production, ecosystems and other purposes. Increases in temperature, changes in rainfall patterns, sea level rise, and extreme events could diminish water quality in Southern Africa. In Mozambique the continued saltwater from rising sea level and storm surges threaten water supplies in coastal areas and on small islands.

Increasing heat stress will significantly increase water requirements for livestock, resulting in overgrazing near water points. As a result causing land degradation and endanger biodiversity. Climate change and variability have the potential to impact negatively on water availability and access to and demand for water in most countries, but particularly in Africa [10](IPCC, 2007). Changes in water quantity and quality due to climate change apart from affecting water sources for livestock, are also expected to reduce the pasture species biodiversity of the rangeland. This increasing the vulnerability of livestock production which is predominantly grassland based. There is a larger degree of uncertainty about future impacts of climate change on water resources than about climate variability [23](Kahn and Hanjra, 2009). Water resources are inextricably linked with climate change, so the prospect of climate variability has serious implications for water resources in Southern Africa. The persistent drought in some parts of the region has worsened the situation livestock losses have been experienced. The scarcity of water due to climate variability has affected two important variables which influence livestock production which are rainfall and temperature. Climate change as a multiplier effects on other factors affecting water resources [24](Tadesse, 2010). In the region the impact of climate change has lead to additional pressure on water availability, accessibility, supply and demand for livestock. Some countries such as Zimbabwe are already experiencing considerable water stress in some parts of the country as a result of insufficient and unreliable rainfall hence more frequent dry spells are expected to increase the likelihood of livestock capacity decline. Climate change induced flooding due to rise in sea water level have been experienced in Mozambique. In such these cases cconsidering the expectation of more frequent droughts and floods, the forecast of river flows and its interaction with extreme variation in precipitation becomes crucial to mitigate the effects of climate change. Climate change can often exacerbate water problems for instance where climate change has led to overgrazing in some areas which then suffer rapid runoff and flooding. Frequent droughts might be a cause of concern in terms of disease and parasites distribution and transmission, apart from the physical losses of livestock. Water which include rivers, dams/ponds, bore-holes, wells and springs dry up during the dry season due to extreme temperatures Livestock production in such cases faces a lot of challenges associated with watering animals, resulting in animals herded for long distances. Access to water for livestock production is predicted to become more challenging with the continued onset of climate change. Strategies to adapt to water scarcity need to be put in place to decrease climate vulnerability and ensuring that water management practices cope with increased climate variability. Controlling use of water as a means of slowing the effects of climate change and sustain livestock production should be should be a priority. Wetland protection may be one of the strategies to ease on water shortage in some parts of the region, especially the semi arid areas. These may act reservoir future water use through raising the water table to acceptable levels. However most of 
the time wetlands have been used for human settlement to the detriment of water use. Lack of water and increased frequency of drought in certain countries will lead to a loss of livestock resources.

\section{Impact Of Climate Change On Livestock Health}

It has been known that climatic variations can influence livestock health, particularly through changes in temperature and precipitation, as well as extreme weather events [25](Skuce et al., 2013). Current evidence points to scientific consensus about the existence of climate change which has rekindled interest in linkages between climate and livestock health. The potential range of impacts of climate change on livestock production is wide and they have been reviewed extensively [20](ISS, 2010; [10]IPCC, 2007). There are a number of approaches to studying the potential livestock health impacts of climate change. These include studies of the associations between past climate variability and disease; of the associations between trends in climatic variables over recent decades and the epidemiology of diseases; and of the response of vector species to changes in temperature and rainfall. In addition, there have been a number of approaches to modeling the potential future impacts of climate change on health. Expression of many livestock diseases and parasitic infestation are known to be climate dependent causing devastating illness and loss of body condition resulting in reduced animal performance. Livestock health may be affected by climate change in four ways: heat-related diseases and stress, extreme weather events, adaptation of animal production systems to new environments, and emergence or reemergence of infectious diseases, especially vector-borne diseases critically dependent on environmental and climatic conditions [26](Forman et al., 2008). In Southern Africa climatic change induced environmental conditions are favorable to most major vector borne diseases and parasites. Environmental changes are likely to influence changes in disease epidemiology, however, their effects may be difficult to predict, posing challenges on conventional disease control methods. Several examples illustrate how variations in climate-in the form of floods, droughts, and other extreme weather events-influence the range and transmission dynamics of infectious diseases, and therefore suggest potential effects of climate change [27]( Institute of Medicine (US), 2008). Climate variability may accelerate the pace of ecological upheaval and disease epidemiology inherent complexity to climate change due to extreme weather events. These scenario inspire both uncertainty and urgency in the quest to better understand, anticipate, and respond to the potentially wide-ranging livestock health effects of climate change. Climate change-related effects are likely to increase the importance of genetic resistance and tolerance in disease control strategies. How critical climate change could become a threat to livestock production has been studies for several risk settings, which include occurrence of new cases of livestock diseases and parasites, due to changes in environmental conditions. Climate change could indirectly affect livestock production by influencing the emergence and distribution of livestock disease and parasites, exacerbating the frequency and distribution of adverse weather conditions [28](Waston et al 1998. On the other hand, climate variability have a direct influence on the epidemiology of vector-borne diseases and parasites and this evidence has been assessed in order to determine the possible consequences of the expected future climate change [29](Githeko et al., 2000). Livestock disease occurrence is based on disease ecology and transmission dynamics which can be influenced by environmental conditions. Bacterial, viral disease and parasitic infestation will be greatly influenced by changes in rise in temperature and humidity. Heat related mortality and morbidity will take its toll on livestock production as a result of climatic variability. Temperature sensitive diseases will be on the increase which may be considerable in high humidity and flooded areas. Disease challenges have already indicated that they are a major constraint to the improvement of the livestock industry in the tropics [30](Devendra et al 2000). This has been attributed to the effect of diseases on reducing production and increasing morbidity and mortality [31](Mwacharo and Drucker 2005). The responsibility for maintaining diverse indigenous livestock as a strategy against serial disease mutation may fall increasingly to national governments. Diseases are adapting ever faster to new drugs and strains of related infections, arising ever more rapidly with clear parallel in livestock production. In this case the indigenous livestock will have a range of tolerance of disease pathogens and the unadapted livestock, especially imported ones, will suffer more mortality. With the uncertainty of climate change disease cycle will be unpredictable and sporadic outbreaks may occur and the most viable strategy in the context of climate change is to retain more of the adapted indigenous livestock and take a risk on an epizootic not occurring within an economic cycle. It is seems sometimes that advocates of the conservation of indigenous livestock biodiversity take up a fundamentalist position that propose the elimination of all high input-high output livestock. This view emanate from the realisation of the future consequences of climate change on new diseases and parasites occurrence, despite the high output of exotic livestock breeds. The more intense floods in coastal areas of Mozambique, although to some extent relieve the water shortages, the floods will be damaging to livestock infrastructure and resulting in more waterborne disease. Moreover, diseases will spread more easily as water temperatures increase in response to climate change. Freshwater for livestock production will be impacted mainly by increasing variability in rainfall, as well as rising sea levels. Groundwater and surface water will decrease, and increased evaporation from the ground will leave the soils more salty, thereby limiting plant growth. Flooding due to rising sea levels, will 
cause increasing salinization of groundwater and estuaries, leaving less freshwater for livestock production. Livestock health policies should take into account the need to adapt to a changing climate, as well as the potential for near-term benefits to livestock health from a range of policies to mitigate climate change. However our current understanding of the relationships between climate and weather, and epidemic infectious diseases, is insufficient to make credible predictions about future threats posed by livestock infectious diseases and parasitic infestation.

\section{Livestock Production Research In The Context Of Climate Change}

Livestock farmers in Southern Africa have developed several adaptation options to cope with current climate variability, but such adaptations may not be sufficient for future changes of climate. It is imperative through appropriate climate change research to complement their efforts in intensification to climate change adaptation responses in livestock production. However, the truth of the matter is that there is very little coordinated research on climate change in Southern Africa, particularly on addressing livestock adaptation to climatic induced environmental stressors. Although few studies focused on crop production have yielded significant information on vulnerability to climate change. There is a paucity of data relating to vulnerability at community and household levels in livestock production. Little knowledge if not, about livestock vulnerability is not matched by efforts towards adaptation, and very little is available in the way of adaptation response plans to sustain livestock production. Research should focus on the unveiling the understanding of the drivers of climate change and their complex interactions. Successful anticipatory adaptation requires the best available information concerning the nature of future climate risks: therefore it is vital that climate science is used more effectively in adaptation decision making. Severe lack of local research weather data has made it impossible to validate climate models and hence predict with any degree of accuracy what will happen as a result of climate change at regional or country level. This lack of data to predict the effects of climate change has implications in terms of designing adaptation measures to cope with high levels of uncertainty associated with climate change. It has been acknowledged that this has made the understand of the effects of climate change fraught with difficulties. While some progress has been made in crop production, little is known for livestock production. There is still great uncertainty about the key climatic processes and their consequences on livestock production especially for small scale livestock farmers. Additionally, while local communities have developed many varied ways of coping with perennial droughts, very few studies have systematically recorded its implication on livestock production. Research on adaptive capacity related to climate change is needed in order to empower livestock farmers deal with climate change issues beyond what they have experienced previously. Quantitative simulation studies that estimate the effect of possible future climate change in livestock production are not possible due to limitation of funding or personnel knowhow. However, the effect of weather and extreme events on several aspects of animal production has been well documented [32](Adams et al., 1999; [14]McCarthy et al., 2001; [33]Parons et al., 2001; [34]Chase, 2006; [15]Seo and Mendelsohn, 2008). Lack of technical knowledge in climate change risk averseness has made the response climate change challenges a nightmare in Southern Africa. The principal research focus need to improve the overall biological and economic efficiency of indigenous livestock without compromising their adaptability traits. Livestock research should be centred on adaptation than productivity alone which augur well with the uncertainties of climate change. The success of this approach will depend on the provision of an optimized genetic potential fulfilling program which incorporate the subsistence farming system where the indigenous livestock genetic resources are numerous. Livestock production priorities should be directed towards promoting livestock genetic resources by providing comprehensive research support services on the impact of climate change. Livestock improvement focus of indigenous livestock should not be narrowed to criteria of commercial systems alone, but should take into account the ability of livestock to cushion themselves to the negative impacts of climate change. The role of livestock production in farming systems, as they offer opportunities for risk coping, farm diversification and intensification, and provide significant livelihood benefits and food security should be acknowledged. Southern Africa has been lagging behind in research in climate change related issues which has resulted in lack of insufficient understanding of climate change and its impact on livestock production. This has prevented progress in combating the effects of climate change in livestock production in the region. It would be a grave disservice endangering the indigenous livestock due to inappropriate responses to climatic variability induced factors. The unrecoverable loss of adapted livestock species should in any case be avoided in the context of climate change. Most populations of indigenous livestock species have been subjected to little or no deliberate selection for higher productivity, this in itself gives indigenous livestock an upper hand in the ability to reproduce and survive in the context of climate change. Most selection programs to improve productivity did not take into account survival of animals in stressful environment. Its reasonable to suggest that adaptability in animals was compromised to some extent. Preferred breeding objectives did not respond to the demands of climatic variability and low input system making the outcome of such improvement programs incompatible with the expected impacts of climate change in livestock production. It is suffice to say on contrary, the introduced 
livestock breeds may severely succumb to the challenges of climate changes than the indigenous livestock species resulting decline in their productivity. The major concern for using indigenous livestock genetic resources is their adaptive traits which will be more important in climate change variability and other common environmental shocks if livestock production is to be sustained. The major challenges of livestock research in the context of climate change is to improve livestock productivity potential to a satisfactory level without sacrificing adaptational qualities. Efficiency of livestock and crop production has too often in the past been measured only in terms of their productivity, whilst the efficiency to survive and produce in stressful environment was ignored. Investment in livestock research and sharing knowledge of sustainable and climate friendly livestock farming practices is crucial. Regional-specific coordinated research is needed to inform the development of adaptive strategies to address the climatic variability issues. To reduce livestock farmers' vulnerability to climatic variability, there need to be a sharper focus on characterization of indigenous livestock breeds, as well as more sustainable and integrated management of these animals to the dwindling feed resource base that sustain their production. Livestock producers have traditionally adapted to various environmental and climatic changes by building on their in-depth knowledge of the environment in which they live. However, the expanding human population, urbanization, environmental degradation and increased consumption of animal source foods have rendered some of those coping mechanisms ineffective [35](Sidahmed, 2008). It is assumed that changes brought about by climatic variability are likely to overtake the capacity of spontaneous adaptation of livestock species.

Lack of institutional capacity to address the issues pertaining to climate change has been visible in southern Africa. Vital institutions which deal with climate change related support services such as Water Authorities, Meteorological Services Departments, Department of Agricultural Research and Extension and Department of Civil Protection have capacity constraints. Donor programs on climate change in specific countries continue to work individually and without coordination at regional level, resulting in duplication or sometimes dwelling on inappropriate or irrelevant approaches to climate change adaptation issues. There should be regional focus on climate mitigation strategies under a coordination mechanism dedicated solely to climate change issues related to livestock production, if appropriate mitigation strategies are to be developed. Assessment of climate change constraints to livestock production for the purpose of setting sound research priorities is required. Livestock production issues related to climate change have not been reasonably researched and simply not known locally. Research on indentifying adaptive measures and estimating the determinants of adaptation strategies to climate change in livestock production is scarce in Zimbabwe. Definition of comprehensive livestock production strategies incorporating specific, immediate and long term ecological constraints as a result of climate change was found lacking in most livestock projects that has failed. Specific or targeted research related to climate change which give solutions to ensure sustenance of individual ecosystems and its herbage and tree shrubs cover and of grazing livestock species for the future taking into account the climatic variability are necessary. The events in terms of livestock research in Africa have been compromising adaptational traits on the expense of livestock productivity, as a result many livestock species will be unable to cope with the effects of climate change in future if the breeding objectives are not changed. Livestock research should be redirected to consolidate the already adaptational traits which indigenous livestock species posses. The focus of livestock research should change to encompass the animals ability to survive in stressful environment. Indigenous livestock research locally has been driven by the desire that the local livestock species should match their counterpart in Europe in terms of productivity. With climate change events taking the centre stage such research focus may be counter productive. Indigenous livestock species which are adapted to the harsh environmental conditions have unfortunately been crossed with imported genotypes which are less tolerant to local diseases and less well adapted to the changing environmental conditions but produce better than indigenous livestock only when the management is modified. It is reasonable to suggest that this research trend imposed on Africa does not take cognisance of the unforeseeable negative effects of climate change on the continent which has been predicted to be graver than on any other continent. Research on livestock adaptive measures and capacity need conservable attention to reduce vulnerability especially in smallholder livestock sector. Research geared at development of collaborative work by all stakeholders to support the adaptation of livestock systems to better cope with the negative impact of climate change will be critical. However it is not possible drastically to change the livestock production culture of the livestock producers especially the smallholder farmers for at least for decades to come. To achieve success in livestock research in the context of the uncertainties of climate change it is necessary to look at livestock production system holistically and involve smallholder livestock producers at every stage in the planning and integrating the traditional values on climate change. It is also important that livestock research should have a component of subjecting animals to simulated impacts of climate change. This will assist in substantiating the responses of livestock to nutritional stress, water deprivation and increase in environmental temperatures.

Extension contact increases adaptation to climate change which implies that extension services are important for reducing the negative effects of climate change on farmers by disseminating climatic information 
as well as agricultural management practices [36](Nkeme and Ndaeyo, 2013). Livestock farmers need to be exposed to extension services for awareness creation and climate change innovation adoption to mitigate its effects on livestock production. It seems that commercial livestock producers have access to extension information concerning climate change forecasting, adaptation options and livestock management practices to mitigate the effects of climate change. It is highly unlikely or decrease the probability that smallholder livestock farmers may take up adaptation measures to ameliorate the effects of climate change because of poor flow of information from extension to farmers. Indeed, regional cooperation within and outside Southern Africa is vital to mitigating the risks of climate change to livestock production.

\section{Indigenous Livestock Utilization As A Mitigation Strategy}

Livestock production systems vulnerability is dependent on a host of factors which include exposure and sensitivity of climate change impacts, the degree of impacts and the capacity to adapt to the impacts. The understanding of climate change variables and their complex interactions is the first step or prerequisite for defining appropriate adaptive responses to lessen vulnerability to climate variability. To achieve sustainable livestock production, production systems should be compatible with the challenges of curbing the effects of climate change. Often than not, the failure to quickly adjust to the changes in the environment may break the link of adaptation between livestock and their production environments. In such circumstances, adapting livestock management to the effects of climate change will present a host of challenges. One of the feasible option of adapting to climate change effects in livestock production is promoting local indigenous livestock species. Indigenous livestock species represent a genetic resource which is resilient to climate variability and should not only be conserved for future use but also utilized as a potential tool to mitigate against climate change effects. Livestock indigenous to Southern Africa have shown high degree of heat tolerance, are partly resistant to many local disease and parasites and can survive in the context of scarce feed resources. Accelerated climate change may outstrip the ability of exotic livestock to adapt genetically or that of livestock producers to adjust their management strategies in response to climatic changes. Indigenous goat breeds have the ability to survive dry periods of feed scarcity and water shortage, and their feeding behaviour has both browsers and grazers have been compatible with harsh environmental conditions. It is reasonably to suggest that their adjusted behavioural or physiological characteristics to survive in harsh environment have become genetic for the simple reason that they have been acquired by natural selection over hundreds of generations. However these characteristics have become essential for sustainable livestock production in the context of climatic variability. Indigenous livestock genetic resources have co-evolved in stressful environment over millennia and have adapted to different prevailing agro-ecological environment in Southern Africa. The small scale livestock farming which is characterised by generally low input-output system is dominated by indigenous livestock breeds, which may suggest less vulnerability to climate change. The ability to switch to other livestock enterprise such as small ruminant give flexibility to small scale famers to deal with climate change, however this is limited by resources which makes small scale livestock farmers more vulnerable.

Climate change is expected to determine the decrease in large ruminants and increase the use of small ruminants due to harsh environmental conditions. Small scale livestock farmers are generally more sensitive to droughts than large commercial livestock farmers, due to their direct dependence on rainfall for their enterprises. However large commercial livestock farmers may suffer bigger financial losses due to drought than small scale farmers. Small scale livestock farmers tend to have an advantage in the context of climate change over the large livestock producers mostly due to the utilization of indigenous livestock species which are well adapted to the harsh environmental conditions, which culminate to lesser threat to climate change. Most large commercial livestock producers use high-output livestock breeds that are not well adapted to heat stress making them highly vulnerable to climatic variability. If resources are improved small scale livestock farmers may be generally less vulnerable to climate change. Availability of resources have a bearing on the capacity to survive drought. Clearly the magnitude of a climate impact, such as the duration of a drought, also plays a part in determining vulnerability. The more vulnerability of large ruminants than small ruminants will force farmers to reduce population numbers of the large ruminants in the commercial livestock sector. The expected performance of animals which is extremely high for commercial livestock entities will suffer tremendously in the context of climate change. This will obviously affect the net income which is major component of commercial livestock farming.

In the case where indigenous livestock breeds are to be promoted there is need to revisit the animal improvement objectives. The genetic livestock diversity of Southern Africa give a range of strategic options that are likely to be valuable in climate change adaptation, including resistance and tolerance to specific diseases, adaptation to poor-quality diets or to feeding in harsh conditions, and tolerance of climatic extremes. Livestock improvement options to improve the animals' abilities to cope with several climate-change related problems are possible and are likely to become increasingly important in the future. The trend where livestock improvement objectives had focus on productivity alone may not work in the context of climate change. The utilization of 
livestock breeds in climate change adaptation requires to emphasize on adaptational traits, which produce animals for their current and potential future production environments which are expected to be harsh. Therefore it is imperative that improvements, characterization and conservation of indigenous livestock genetic resources becomes essential.

\section{Implications}

Southern Africa's livestock production systems diversity and its dependent on rangeland is highly vulnerable to climatic variability. Climate change is coming as an additional factor affecting livestock production that is already highly dynamic and facing a host of challenges. Livestock production is one of the core sectors which plays an important role in food security. With this in mind, it is crucial to mitigate possible impacts of climate variability on livestock production if challenges of food insecurity are to be addressed. Sustainable livestock production ensuring that food security is achieved, no longer represent only a legitimate aspiration for Southern Africa, but constitute a compelling strategy to address the current food crisis and respond to the negative impacts of climate change. Appropriate adaptive responses to address the many severe climatic induced vulnerability are a necessity in livestock production if capacity decline is to be arrested. The capacity to adapt to climate change can influence how climate change affects the region in terms of livestock productivity. Southern African is already experiencing considerable water stress as a result of insufficient and unreliable rainfall hence more frequent dry spells are expected to increase the likelihood of livestock capacity decline. As the adverse impacts of climate change become more frequent and severe, livestock producers need to be equipped to deal with climatic variability with the objective of sustaining livestock production. The strategy in active livestock improvement should focus on the optimization of indigenous animal genetic resources potential according to different production factors, the needs of the market, the ecological environment and future developments, at the same time addressing the issues related to climate change. It is the argument in this discussion that with the foreseeable harsh environmental conditions induced by climate change, the promotion of the utilization of indigenous livestock in Southern Africa should be intensified. The influence of water stress and disease resistance as predicted in the context of climate change should be studied further and appropriate adaptive capacity responses put in place to maximize livestock productivity. Research prioritization should be guided by demands from livestock farmers to curb the negative effects of climate change to sustain animal production in order to enhance food security. All future livestock research focus should have an element of testing livestock in stressful environment. This can be done through simulation studies, however consideration should be made not to compromise adaptive traits in local livestock. Efforts should be made to further characterize indigenous livestock taking into account possible desirable qualities needed in future livestock production targeting at counteracting the negative effects of climate change on livestock production. It is indisputable that multiple climatic induced stressors are likely to increase livestock vulnerability, hence it is imperative that adaptive solution are sort.

\section{References}

[1] M Miraglia, H.J. Marvin, G.A. Kleter, P. Battilani, C. Brera, E. Coni, F. Cubadda, L. Croci, B. De Santis, S. Dekkers, L. Filippi, R.W. Hutjes, M.Y. Noordam, M. Pisante, G. Piva, A. Prandini, L. Toti, G.J. van den Born, and A. Vespermann, Climate change and food safety: an emerging issue with special focus on Europe. Food Chem Toxicol 47, 2009, 1009-1021.

[2] P. Van den Bossche, and J.A. Coetzer, Climate change and animal health in Africa. Rev Sci Tech 27(2), $2008,551-562$.

[3] S Forman, N Hungerford, M Yamakawa, T Yanase, H.J. Tsai, Y.S. Joo, D.K. Yang, and J.J. Nha JJ, Climate change impacts and risks for animal health in Asia. Rev. Sci. Tech. 27(2), 2008, 581-597.

[4] PF Black, J.G. Murray, and M.J. Nunn, Managing animal disease risk in Australia: the impact of climate change. Rev Sci Tech, 27(2), 2008, 563-580.

[5] J Pinto, C. Bonacic, C. Hamilton-West, J. Romero, and J. Lubroth, Climate change and animal diseases in South America. Rev Sci Tech 27(2), 2008, 599-613.

[6] M.T. Usman, and C.J.C Reason, Dry spell frequencies and their variability over southern Africa. Climate Research 26, 2004, 199211.

[7] M.A. Tadross, C. Jack, and B. C. Hewitson, On RCM-based projections of change in southern African summer climate. Geophysical Research Letters 32(23), 2005, L23713, doi 10.1029/2005GL024460.

[8] M New, B. Hewitson, D. B. Stephenson, A.Tsiga, A. Kruger, A. Manhique, B. Gomez, C. A. S. Coelho, D. N. Masisi, E. Kululanga, E. Mbambalala, F. Adesina, H. Saleh, J. Kanyanga, J. Adosi, L. Bulane, L. Fortunata, M. L. Mdoka, and R. Lajoie, Evidence of trends in daily climate extremes over southern and west Africa. Journal of Geophysical Research 111, 2006, D14102, doi:10.1029/2005JD006289.

[9] B Smit, D. Nabb, and J. Snuckers, Agriculture adaptation to climate variation. Climate change. 33, 1996, 7-29.

[10] IPCC, Impacts, adaptation and vulnerability: Contributions of Working Group II to the Fourth Assessment Report, Cambridge University Press, 2007, 444.

[11] D.A. Mwiturubani, Climate change and access to water resources in Lake Victoria basin; In; Mwiturubani Da and van Wyk JA (Ed) (2010) Climate change and natural resources conflicts in Africa, Institute for Security Studies, PO Box 1787, Brooklyn Square 0075, Pretoria, South Africa.

[12] J.T. Houghton, L.G. Meira Filho, B. Lim, K. Treanton, I. Mamaty, Y. Bonduki, D.J. Griggs, and B.A. Callender, (Eds). Revised 1996 IPCC Guidelines for National Greenhouse Gas Inventories, IPCC/OECD/IEA, 1997. available from http://www.ipccnggip.iges.or.jp/public/gl/ invs1 .htm, IPCC NGGIP, Japan.

[13] J.M. Rust, T. Rust, Climate change and livestock production: A review with emphasis on Africa. S. Afri. J. Anim. Sci. 43(3), 2013. 
[14] J. McCarthy, O.F. Canziani, N.A. Leary, D.J. Dokken, and C. White, Climate Change 2001: impacts, adaptation and vulnerability", Intergovernmental Panel on Climate Change (IPCC), (Cambridge University Press, Cambridge UK, 2001).

[15] N. Seo, and R. Mendelsohn, Animal husbandry in Africa. Climate change impacts and adaptation, African Journal of Agricultural and Resource Economics, 2(1), 2008, 65-82.

[16] P. Thornton, and M. Herrero, Climate Change, Vulnerability, and Livestock Keepers: Challenges for Poverty Alleviation. In: Livestock and Global Climate Change Conference Proceeding, May 2008, Tunisia.

[17] Millenium Ecosystem Assessment, 2005.

[18] Food and Agriculture Organization of the United Nations. (2004) Drought impact mitigation and prevention in the Limpopo River Basin: A situation analysis. Land and Water Discussion Paper 4, Natural Resources Management and Environment Department, FAO, Rome, 2004.

[19] J.M. Lenné, and D. Thomas, Integrating crop-livestock research and development in Sub-Saharan Africa - Option, imperative or impossible? Outlook on Agriculture Volume. 35, 3, 2006, 167-175.

[20] nstitute for Security Studies (ISS), The impact of climate change in Africa. Debay Tadesse, ISS Paper 220, November, 2010.

[21] WE Easterling, P.K. Aggarwal, P. Batima, K.M. Brander, L. Erda, S.M. Howden, A. Kirilenko, J. Morton, J.-F. Soussana, J. Schmidhuber, and F.N. Tubiello, Food, Fibre, and Forest Products. In: Climate Change 2007: Impacts, Adaptation and Vulnerability . Contribution of Working Group II to the Fourth Assessment Report of the Intergovernmental Panel on Climate Change.Parry, M.L., O.F. Canziani, J.P. Palutikof, P.J. van der Linden, and C.E. Hanson (eds.).(Cambridge University Press, Cambridge, United Kingdom, 2007).

[22] Z.W. Kundzewicz, L.J. Mata, N.W. Arnell, P. Döll, P. Kabat, B. Jiménez, K.A. Miller, T. Oki, Z. Sen and I.A. Shiklomanov, Fresh Water Resources and Their Management. In: Climate Change 2007: Impacts, Adaptation and Vulnerability . Contribution of Working Group II to the Fourth Assessment Report of the Intergovernmental Panel on Climate Change. Parry, M.L., O.F. Canziani, J.P. Palutikof, P.J. van der Linden and C.E. Hanson (eds.). Cambridge University Press, Cambridge, United Kingdom, 2007.

[23] S. Khan, and M.A. Hanjra, 2009. Footprints of water and energy inputs in food production - global perspectives. Food Policy, 2009, 34, 130-140. (Available from http://www.sciencedirect.com/science/article/pii/S0306919208000729)

[24] D Tadesse, Climate change, water and food security in Ethiopia. In; Mwiturubani Da and van Wyk JA (Ed) (2010) Climate change and natural resources conflicts in Africa, Institute for Security Studies, PO Box 1787, Brooklyn Square 0075, Pretoria, South Africa, 2010, 81-101.

[25] P Skuce, E. Morgan, Jan van Dijk, and M. Mitchell, Animal health aspects of adaptation to climate change: beating the heat and parasites in a warming Europe GGAA2013, Dublin, June $24^{\text {th }}, 2013$.

[26] S Forman, N. Hungerford, M. Yamakawa, T. Yanase, H.J. Tsai, Y.S. Joo, D.K. Yang, and J.J. Nha JJ, Climate change impacts and risks for animal health in Asia. Rev. Sci. Tech. 27(2), 2008, 581-597.

[27] Institute of Medicine (US) Forum on Microbial Threats, Global Climate Change and Extreme Weather Events: Understanding the Contributions to Infectious Disease Emergence: Workshop Summary. Washington (DC): National Academies Press (US); 2008. 1, Climate Change Challenges. Available from: http://www.ncbi.nlm.nih.gov/books/NBK45742/.

[28] R.T. Watson, The regional impacts of climate change: An assessment of Vulnerability, (Cambridge University Press Cambridge, 1998).

[29] A.K. Githeko, S.W. Lindsay, U.E. Confalonier, and J.A. Patz, Climate change and vector-borne diseases: A Regional Analysis. Special Theme. Environment and Health. Bulletin of World Health Organization,2000, 78(9).

[30] C Devendra, D Thomas, M Jabbar, and E Zerbini, Improvement of Livestock Production in Crop-Animal Systems in AgroEcological Zones of South Asia., ILRI, Nairobi, Kenya, 2000.

[31] J.M. Mwacharo, and A.G. Drucker, Production objectives and management strategies of livestock-keepers in Southeast Kenya: implications for a breeding programme. Tropical Animal Health and Production. 37(8), 2005, 635-52.

[32] R Adams, B. McCarl, K. Segerson, C. Rosenzweig, K. Bryant, B. Dixon, R. Conner, R. Evenson, and D. Ojima, D. The economic effects of climate change on US agriculture", in Mendelsohn, R. and Neumann, J. (Ed.), The Impact of Climate Change on the United States Economy,(Cambridge University Press, Cambridge, UK, 1999).

[33] D.J. Parons, A.C. Armstron, J.R. Turnpenny, A.M. Matthews, K. Cooper, and J.A. Clark, "Integrated models of livestock systems for climate change studies", Global Change Biology, 7, 2001, 93-112.

[34] LE Chase, Climate change impacts on dairy cattle. Fact sheet, Climate Change and Agriculture: Promoting Practical and Profitable Responses", available from: http://climateandfarming.org/ pdfs/FactSheets/III.3Cattle.pdf. (accessed on June 2006).

[35] A Sidahmed, Livestock and Climate Change: Coping and Risk Management Strategies for a Sustainable Future. In Livestock and Global Climate Change conference proceeding, Tunisia, May 2008.

[36] K.K. Nkeme, and N.U. Ndaeyo, Climate change and coping strategies among peasant farmers in Akwa Ibom state, Nigeria Int. J. Basic Appl. Sci. 2(1), 2013, 24-28. 